\title{
Intracavernous papaverine for impotence in spinal cord injured patients
}

\author{
V K Kapoor MS MCh, A S Chahal MS FRACS, S P Jyoti MS, Y J Mundkur MS, \\ S V Kotwal MS MCh, V K Mehta MS MCh
}

Spinal Cord Injury Centre, Military Hospital, Kirkee, Pune, India.

The majority of the spinal cord injury patients in our centre are young healthy males aged between 20 and 40 years. Loss of erection and inability to have coitus and father children have been responsible for inadequate sociosexual rehabilitation. In 1985, under urologist supervision, intracavernosal papaverine injection treatment was started in 101 volunteers, 65 paraplegics and 36 tetraplegics. Satisfactory erection sufficient for coital penetration was possible in 98 patients. Three had prolonged erection lasting beyond 4 hours. Only one required irrigation of the corpus with saline to achieve detumscence. One patient developed cavernosal fibrosis necessitating discontinuing the injection. Administration was under medical supervision so that possible complications of priapism/systemic effects could be promptly managed.

Keywords: spinal cord injury; impotence; intracavernous papaverine.

\section{Introduction}

Spinal cord injury (SCI) often severely affects genital and sexual function. Sexual rehabilitation in SCI patients has assumed an increasingly dominant role in the overall rehabilitative process as is mentioned by Berkman et al. ${ }^{1}$ The majority of SCI patients are young men faced with sexual doubts, fear and anxieties which must be dealt with in the process of rehabilitation. Like able bodied people, they are entitled to a satisfactory sex life. The use of penile prostheses or rectal aids for treatment of impotence in general is not yet widely practised in this country due to socioeconomic factors. Further, the implantation of penile prostheses in SCI patients has high complication rates according to Rossier et $a l^{2}$ and Van Arsdalen et al. ${ }^{3}$ Local intracavernous injection of papaverine can provoke erection sufficient enough for coitus.

The aim of the present study is to evaluate the role of the intracavernous injection of

Correspondence: Senior Advisor (Surgery \& Urology), Command Hospital, Southern Command, Pune-40, India. papaverine in the management of impotence in these patients.

\section{Materials and methods}

Between 1985 and 1992, of 300 SCI patients admitted to the Paraplegic Center and Home, Kirkee and the Command Hospital, Lucknow, 150 male patients reported sexual dysfunction. A group of 101 patients volunteered to use a local intracavernous injection of papaverine hydrochloride. Their age varied from 20 to 51 years. No participant had been injured less than a year. The neurological lesion level ranged from $\mathrm{C} 4$ to L4. There were nine complete and 27 incomplete tetraplegic patients, and $23 \mathrm{com}$ plete and 42 incomplete paraplegic patients. Eighty-six \% were married and 14\% unmarried. All participated in a series of information and counselling sessions on sexual problems. All were interviewed by the investigator, personally and professionally before embarking on the use of intracavernous injections of papaverine.

All patients had baseline urine, haemoglobin, liver function tests (LFT) and electrocardiogram (ECG). LFT and ECG were 
repeated every month. No special tests for impotence were done as the cause was presumed to be neurological.

The penis was cleaned with Savlon and dried. Training consisted of demonstration of the sterile injection technique with 1-2 $\mathrm{ml}$ disposable syringe with $3 / 8$ inch, 26-27 gauge needles (tuberculin or insulin needles serve well). The injection was given in the posterolateral aspect of the penis at the base, making certain that the corpus cavernosa was penetrated as determined by a characteristic give as the needle penetrated the tunica albuginia. The syringe was held perpendicular to the skin at the injection site. Steady pushing against the penile shaft held between the index finger and thumb will penetrate the corpus cavernosum. It was not necessary to aspirate blood from the corpus. Papaverine hydrochloride was then injected slowly. Firm compression at the site of injection was applied for 5 minutes to avoid bleeding and subcutaneous haematoma. Lag period, ie time taken between injection and achievement of full erection, and duration of erection were also noted. Patients staying with family were allowed to go home and were interviewed later regarding their sexual performance and the satisfaction of themselves and their partners. Initially a dose of $7.5 \mathrm{mg}$ papaverine was used. The dose was increased according to the status of erection. The patient learnt the technique of self injection, but if this was not feasible the patient's partner or attendant was taught. Once satisfactory erection was achieved, patients were issued with the drug and were advised to use it 2-3 times a week.

The patients were followed at monthly intervals, and were questioned in general terms on concurring frequency of coitus, results of erection, pain and possible deviation of the penis. The penis was checked for possible chordee, induration etc.

\section{Observations and results}

All the patients in the younger age group (up to 30 years) required $7.5-15 \mathrm{mg}$ of papaverine to achieve a good erection (Table I). The older age groups required a higher dosage. Seventy-eight patients had a good erection within 10 minutes (Table II). Three patients had a poor response even after half an hour. Ninety-eight patients achieved good erections and enjoyed coitus, with their spouse at the Paraplegic Home or when they visited their own home.

The unmarried SCI patients having achieved erections with papaverine were keen to get married. Duration of erections is summarised in Table III. Complications are listed in Table IV. One patient developed priapism and required saline irrigation of the corpus cavernosa to achieve detumescence.

Table I Dose-erection relation

\begin{tabular}{lccc}
\hline Dose (mg) & \multicolumn{3}{c}{$\begin{array}{c}\text { Age (years) and number } \\
\text { of patients }\end{array}$} \\
\cline { 2 - 4 } & $20-30$ & $30-40$ & Over 40 \\
\hline 7.5 & 38 & 2 & - \\
$10-15$ & 21 & 16 & - \\
$15-30$ & 5 & 7 & 2 \\
$30-60$ & - & 21 & 6 \\
$\begin{array}{l}\text { Total number of } \\
\text { patients }\end{array}$ & 64 & 26 & 8 \\
\hline
\end{tabular}

Table II Lag period for onset of erectile rigidity

\begin{tabular}{cc}
$\begin{array}{c}\text { Lag period } \\
\text { (minutes) }\end{array}$ & $\begin{array}{c}\text { Number of } \\
\text { patients }\end{array}$ \\
\hline 10 & 78 \\
20 & 13 \\
30 & 07 \\
\hline
\end{tabular}

Table III Duration of erection

\begin{tabular}{lc}
\hline Duration (hours) & Number of patients \\
\hline Less than 1 & 35 \\
$1-2$ & 29 \\
$2-3$ & 21 \\
$3-4$ & 10 \\
More than 4 & 03 \\
\hline
\end{tabular}


Table IV Complications

\begin{tabular}{lcl}
\hline Complications & Number of patients & Remarks \\
\hline Subcutaneous haematoma & 3 & Resolved \\
Cavernosal fibrosis & 2 & Dosage frequency reduced \\
Prolonged erection (more than & 3 & $\begin{array}{l}\text { One required cavernosal wash with } \\
\text { d hours) }\end{array}$ \\
Systematic effects & 1 & Dosage reduced \\
\hline
\end{tabular}

\section{Discussion}

Changes in sex life and anxiety about fertility are major factors determining the course of rehabilitation in the spinal cord injured. Erection is affected more frequently in those with low spinal injuries. ${ }^{4}$ This was also seen in our series $(65 \%)$. Penile implants, though popular in the developed world, are not without ill effects. Penile prostheses have not been used because of socioeconomic factors, as well as from the lack of experience and facilities for prosthetic implantation in India. However, with increasing awareness, this form of treatment will be offered to selected patients.

The majority of our young patients (less than 30 years) could achieve erection with $7.5-15 \mathrm{mg}$ of papaverine. Erections occurred within 10 minutes. Rapidity of onset has an advantage. Even if the lag phase is prolonged, erection for penetration occurs mostly after the initiation of coital activity. Dosage was increased in increments until adequate erections were obtained. Ninetyeight had a good erection and sexual performance was rated as good as prior to injury. Erection lasted for between 1 and 4 hours in 95 of the patients and ensured partner satisfaction. If prolonged erection of more than 4 hours occurred the patient was advised to report immediately and the corpus cavernosa were irrigated with saline or dilute solution of dopamine $(1 \mathrm{mg} / \mathrm{ml})$. This helps in preventing priapism. The apprehension that side effects of papaverine injected intracavernosally will severely restrict its use have been dispelled. ${ }^{5,6}$ These authors monitored blood pressure, pulse and ECG for up to 2 hours after the papaverine injection and no appreciable changes could be detected. Slow circulation of the drug from the venous system of the corpora into the general venous system probably minimises systemic side effects. Vasovagal reactions (bradycardia, hypotension, dizziness and facial flushing) are uncommon and were seen in only one patient in our series, being dose related $(30 \mathrm{mg}$ of papaverine was used).

Two of our patients developed cavernosal fibrosis after prolonged use (over 36 months). The use of papaverine was stopped in these patients. This is a limiting factor with papaverine, since a $\mathrm{pH}$ of about 3 to 4 with this agent will cause fibrosis, as was noted by Nelson. ${ }^{7}$ Thus it is important that doses of papaverine be kept minimal.

\section{References}

1 Berkman AH, Weissmen R, Frielch M (1976) Sexual adjustment of spinal cord injured veterans living in the community. Arch Phys Med Rehabil 59: 29-33.

2 Rossier A, Fam BA (1981) Indication and result of semirigid penile prosthesis in spinal cord injury patient: Long term follow up. J Urol 131: 50-62.

3 Van Arsdalen KN, Klein FA, Hachler RH (1981) Penile implants in spinal cord injury patients for maintaining external appliances. J Urol 126: 331-332.

4 David A, Ohry A, Rozin R (1987) Spinal cord injuries: male infertility aspects. Paraplegia 15: 11-14.

5 Zorgniotti AW, LeFleur RS (1985) Auto injection of the corpora covernosa with a vasculogenic drug combination for vasculogenic impotence. J Urol 133: 39-41.

6 Jünemann KP, Luet F, Fournier GR, Tangaho EA (1986) Haemodynamics of papaverine and phentolamine induced penile erection. J Urol 136: 158-161.

7 Nelson RP (1987) Pathophysiology, diagnosis and management of erectile dysfunction. In: Rous S, editor. UROL Annual. Appleton \& Lange, Norwalk, Connecticut: 139-169. 